the chapter following the description of the picturebook session could have been a bit more neatly organised to allow the reader to follow the text more easily, but this paper still offers a fresh perspective on using picturebooks in learning other languages.

Part 2 comprises chapters on early language learning in Cyprus (Sophie IoannouGeorgiou), on introducing French to pre-primary children in England (James McElwee), on a broader and integrated approach to languages in the same age-group (Mónica Lourenço and Anna Isabel Andrade), on active listening (Teresa Fleta) and on the role of technology in early years SLL (Barbara Hoskins Sakamoto).

The first two chapters in Part 3 focus on pre-primary English language learning and teacher education in the Czech Republic (Monika Černá), and in Slovakia (Zuzana Portiková). The remaining chapters explore teachers' attitudes to innovations in SLL (Ekaterina Sofronieva), family involvement (Sabine Pirchio et al.), and supporting parents of young learners (Alexander Sokol and Edgar Lasevich).

It can be concluded that this book is a rich reading experience for all who are in any way involved in second or foreign language education. Researchers, academics, teachers and students could all find it useful, especially teachers of young and very young learners who use authentic picturebooks in teaching. Offering a variety of contexts, methodologies and approaches, it gives a wide picture of language learning as a dynamic process, while highlighting the basis of education and the fact that children's nature is often neglected when complex frameworks are created.

Mateja Lovreković

\title{
A Secret World of the Translation Process
}

Gillian Lathey. 2016. Translating Children's Literature. London and New York: Routledge. 172 pp. ISBN 978-1138803763

DOI: 10.21066/carcl.libri.2016-05(01).0024

Gillian Lathey's delightfully readable Translating Children's Literature gives the impression of being a tête à tête in which she shares much personal knowledge and expertise of translation over the years. This she supports with fascinating references to the work of long-standing colleagues, which she interposes alongside her own thinking. Although not a professional translator herself, Lathey's interest in writing Translating Children's Literature stems from a passion in children's literature developed during her early primary teaching career, and later as an academic, as well as from a deep and lifelong interest in the art of translation. Thus she is in an excellent position to discuss the work of so many "invisible storytellers" (Lathey 2010) who make possible the transference of literary works for young children from one culture to another. Her aim, she emphasises, is to "assist would-be translators to act as bridges for the young into worlds of individual writers whose work they would not otherwise encounter" (11).

Lathey's introduction talks directly to prospective translators or those who have just begun to embark on the journey (no matter what their source or target language) and makes them the focus of her dialogue. She emphasises that translating children's literature is a diverse and complex process and is no less challenging than translating for adults. She also 
demonstrates the potential of narrative and linguistic style and points out that, in all cultures, translated children's literature has had "profound effects on the development of national children's literatures" (7). Using many well known examples from the Brothers Grimm and Carlo Collodi, amongst others, to support her argument, she suggests, perhaps to encourage those new to the art, that translating for children may also include more contemporary and experimental texts which will "tax even the most competent of translators" (8). As one would expect, this introduction outlines what is to come and contextualises the book's content with background information on issues such as critical and theoretical interests in translation for children, which can offer fresh insights into specific strategies.

Each chapter is set out in easy-to-follow sections which address different aspects of translation for children, and is accompanied by helpful exercises or questions that can be worked through at the reader's own pace, or used as the basis for seminar structure.

Chapter One focuses on common modes of addressing the child reader, narrative style and the challenges of translating the child's voice. Lathey, quoting Riitta Oittinen, a renowned expert on translation for children, suggests that "the translator should reach out to children of the target culture by attempting to re-experience the dynamic intensity of childhood" (15). Lathey believes that an understanding of children's imaginative, spiritual and emotional concerns is an inestimable advantage to a translator writing for a young audience, whose primary task is to identify the quality of narrative voice in a children's text. When discussing translated extracts from well-known tales such as A.A. Milne's Winnie-the-Pooh and Astrid Lindgren's Pippi Langstrump, plus lesser known translations from Japan and other countries, Lathey ably leads us through the complex and precarious routes the translator has to follow in order to achieve successful communication with young readers. She also points out that layers of meaning for dual audiences should be as apparent in the translation as in the source text. Additionally, she draws on the work of experienced translators like Anthea Bell, Patricia Crampton and Sarah Ardizzone, amongst others, whose experiences will help readers to understand how each translator has managed to find their own very personal translation style which helps them to engage with an imagined child reader.

Chapter Two, entitled "Meeting the Unknown", concerns itself with the translation of cultural markers for young readers and the delicate question of the degree of unfamiliarity children can be expected to assimilate. Here Lathey questions just how far a translator should "mediate" a work of fiction, because young people who rarely encounter other cultures in their reading material may be wary of the unknown (39). However, she suggests that "domesticating" foreign names or milieu, for example, removes an element of excitement from children's reading (38). Again, she supports her argument with numerous examples of the ways in which translators have overcome this problem, including: relocation, cultural explanation, specific cultural markers, glossaries and translating names and place names. Amusingly, she exemplifies how the Englishness of Harry Potter's middle class address in Harry Potter and the Philosopher's Stone is telegraphed through the name of the road in which he lives (48), and goes on to cite the ways in which French, German, Latin, Japanese and Russian translators have coped with this - some more successfully than others!

Chapter Three tackles the visual dimension that has been of central importance to the children's literatures of most cultures, and the translation of the modern picturebook. Translating the visual, Lathey tells us, places creative demands on both the aesthetic and 
visual aspects of children's literature, and she cites Comenius who, as early as 1659 , described the process as "a three way tension between source language, target language and illustrations". More recently Andrea Bell (2006) describes it as a "tightrope walk" for the translator, and Lathey believes that translators have to engage with complex orchestration of text and image that requires an informed understanding of the illustrator's art, multimediality and semiotics. Additionally, she continues, the positioning of text in relation to pictures may require some thought on the part of the translator and quotes Maria Nikolajeva and Carol Scott who emphasise the interdependence of picture and text so that neither would make sense without the other. This chapter is full of fascinating references to the pitfalls that translators can fall into when translating the visual, and includes examples from comic strips such as the Japanese manga which have played a significant role in the development of visual literacy in young readers that is essential in the $21^{\text {st }}$ century. As she does this, she focuses on both linguistic and pictorial elements within the dialogue and stresses the importance of onomatopoeia, as well as inscriptions within images, and shows the relevance of certain typographic elements plus seeing the book as an artefact.

Translating text is the theme of Chapter Four, where dialogue, dialect and street language take the lead, since all three have played a dominant role in modern children's literature, and have also been subject to didactic constraints in some countries. A translator working with spoken language in children's books, Lathey suggests, needs to become acquainted with children's speech patterns and listen to sibling exchanges in order to create a convincing vernacular that will not date too quickly. She convincingly demonstrates this with examples of translated extracts that Cathy Hirano might have used when she worked on Kazumi Yumoto's The Friends. It is clear from this account, and several others, that in-depth awareness of children's speech in both the source and target languages is vital if the transition from one culture to another is to be successful. Linguistic constraints, particularly when relating to languages such as Arabic, Hebrew and Japanese, are also discussed here and Lathey details specific sensitive issues relating to these languages which impose translation limitations. Slang and "street talk", on the other hand, can pose different constraints, especially if a publisher prefers the use of standard English, and Lathey includes a number of pertinent examples to support this. Similarly, she exemplifies how the pitfalls of regional dialect and idiodialect can trap the unwary translator, as can the spoken language of younger children because, as she so rightly points out, it takes great skill and sensitivity on the part of the translator to tune into a young child's voice (87).

Translating sound, the theme of Chapter Five, turns to a crucial creative element in translating for children: read-aloud qualities, wordplay, onomatopoeia and the translation of poetry. Here Lathey covers much ground and provides numerous situations which demonstrate that this task is not as simple as one might think. She believes that, since children of all ages often hear stories rather than read them, translators have a particular responsibility to produce texts that read aloud well. Placing her focus on sound (i.e. the aural and read-aloud qualities of translated prose): on animal cries, wordplay, children's poetry and nonsense rhymes, she lets a number of professional translators explain the reasoning behind their work and chooses words from Sarah Ardizonne to demonstrate this: "You want it to have its own voice and sing for itself" (94). Lathey then suggests that Roald Dahl's The BFG is a case in point - where neologisms such as "snozzcumbers", "human 
beans", "jiggyraffes" and "cattypiddlers" indicate the significance of reading these names aloud. When discussing poetry, Lathey stresses that if juggling four dimensions of meaning: the source language, target language, images and poetic form, a translator has to make choices that may involve sacrifice of one aspect of the text's layers of communication. In addition, especially when translating nonsense verse, the translator has to rely on literary and linguistic knowledge and familiarity with children's poetry to ensure a child-friendly translation.

Chapter Six addresses the continuum between a translation and a retelling, as well as the retranslation and reworking of children's classics and fairy tales. Lathey suggests that the translations of many children's stories may reduce a carefully crafted text to a basic plot line, but there is also great potential for literary creativity. This chapter demonstrates that it is not always easy to establish the dividing line between a translation and a rewriting, explaining a number of factors that can come into play. Strategies for translating folk and fairy tales are exemplified, which include a fascinating and somewhat surprising account of Arthur Ransome's Russian translations. Similarly, the section on translation and retranslation of children's classics makes reference to narratives such as The Arabian Nights, Gulliver's Travels, Don Quixote, Alice in Wonderland and Heidi. Relay translations conclude this chapter, explaining that these occur in cultural and historical contexts where a source text is no longer available.

Chapter Seven, on the current role of translation in the global children's publishing industry, also covers virtual translation and translators working with children, and is a fitting conclusion to a book which gives so many insights into the world of translation for children. It takes the process almost out of the hands of the translator and focuses on extratextual matters such as who decides what gets translated, when and how; the marketing and packaging of children's books; and international developments in children's literature, yet does not forget the important role translators or child readers can play in the publishing process. The chapter is full of advice for young translators but says that "serendipity" (129) does play a part in an individual's success because personal connections with foreign authors, illustrators, translators, editors or agents are by far the most important channels of information about books worthy of translation! Lathey's final section places the child centre stage as translator, reader and respondent, and suggests how the internet is beginning to spawn child translators. She also outlines the importance of translation projects in schools and highlights the Translation Nation project which began in the UK. Finally, she reminds us that to translate for the young is to address the next generation through the voice of a sourcetext author that brings both enjoyment and responsibility - it is demanding yet inspiring.

Having read Translating Children's Literature the impression it leaves is that of being invited into a secret world, full of fascinating insights into the translation process. Lathey, very ably aided and abetted by her numerous linguistically competent international friends and colleagues, invites translators and prospective translators worldwide to share the results of her research, knowledge and expertise. Translating Children's Literature is not only an important read for translators but also an informative source text for all those interested in children's literature, as it gives insights into the literary processes involved in creating and re-creating texts for children, and suggests exciting new ways forward for the $21^{\text {st }}$ century. 